\title{
Ver a cidade
}

\section{uma seleção da literatura periférica}

Antonio Eleilson Leite (organizador) ${ }^{1}$

\section{A Placa}

Rodrigo Ciriaco ${ }^{2}$

A minha aluna virou uma Placa. Há três meses ela deixou de vir à escola por isso: virou uma Placa. E não uma placa qualquer, de trânsito, que ninguém respeita. Ela virou uma Placa publicitária. Agora tem uniforme, endereço e identidade. Não fica mais à margem. Fica na porta dos shoppings, concessionárias e futuros edifícios, se autopromovendo: A Placa. Com pernas.

A minha aluna virou uma Placa. Ela diz sentir muito orgulho da empresa em que trabalha. Construtora. Grande. Bem conceituada. Vende casas de alto padrão, para pessoas de bem, alto poder aquisitivo. Luxo. Seus condomínios têm quadra de tênis, piscinas, bancos; centro de compras particular, segurança e conforto. Diz que a tendência do futuro são os ricos não saírem mais de suas caixas, seus bunkers. Para eles tudo será Prime, Van Gogh. Personalité. A minha aluna virou uma Placa. Aconteceu na porta da escola. Um homem parou o carro importado, abaixou o vidro e disse: - Você leva jeito para Placa. Um cara branco, alto, malhado; peito raspado, gel e gravata. Big boss. Ele não perguntou idade, se tinha experiência ou carteira registrada. Pediu apenas para tirar o óculos, soltar o cabelo. Pronto. Bonita. Está contratada.

1 Universidade de São Paulo (USP), São Paulo, SP, Brasil.

2 Rodrigo Ciriaco nasceu na cidade de São Paulo em 1981. Graduado em História pela FFLCH-USP, leciona na Escola Estadual Francisco Mesquita, na Zona Leste de São Paulo, onde organiza o Sarau Mesquiteiros. Frequenta o Sarau da Cooperifa desde 2005. Em 2008, publicou seu primeiro livro, Te pego lá fora (Edições Toró), do qual foi extraído este conto. Seu segundo livro, 100 mágoas (Edições Um por Todos), foi lançado em 2011. Participou de eventos literários na Alemanha, Itália e França. 
A minha aluna virou uma Placa. Ela diz que trabalha numa empresa ética, séria. Não registram, mas pagam todos os impostos. Todo final do dia ela recebe o seu salário. E vai embora pra casa. A empresa só fez uma exigência: que deixasse a escola. Questão de escolha. O trabalho é das nove da manhã às sete da noite. Segunda a domingo. E sempre há um novo bico. Setor imobiliário em expansão. As propostas estão em expansão. Eles precisam de Placas. Ela já é uma Placa. Quem precisa de estudo?

A minha aluna virou uma Placa. Outro dia, pura sorte, eu a encontrei. Andando sozinha, pela noite, voltava do serviço. Descaracterizada. Não parecia ser a menina frágil da sexta série que até outro dia eu conheci. A menina tímida que sonhava em ser modelo, e só estudava. Falei: - E aí? Você precisa voltar pra escola. Ela respondeu, em tom de deboche: Eu não! Já tinha uma profissão. Tinha seu próprio dinheiro, ajudava a mãe em casa. Responsável, não precisava mais de conselhos, não precisava de mais ninguém. Só do big boss, o chefinho. Aquele que lhe deu valor. Deu emprego, deu presentes, prometeu castelos. O único que não lhe fez se sentir mais como uma qualquer. A transformou numa Placa. Uma Placa-viva. 
Cidade do Sol

Dinha $^{3}$

I

Hoje as palavras são doentes.

Os corpos são doentes

E se juntam num poema

Como se este fosse a cura.

II

Eu não moro em Heliópolis.

Moro em uma pequena vila

Com nome de santa:

Santa Cristina.

É lá que os becos se abrem.

De lá saem as crianças.

(O beco é escuro e a rua

Mais escura que o beco.)

III

Tenho visto muita coisa

(Como todos os poetas)

Também vi pele de homem

Abrindo-se em coisa velha.

E era pra ser visionária

Ver além do que é além.

Mas eu vi pele de homem

Abrindo-se em mais alguém.

3 Maria Nilda de Carvalho Mota, a Dinha, nasceu na cidade de Milagres, Ceará, em 1978. Migrou para São Paulo quando tinha um ano de idade. É mestre em Estudos Comparados de Literaturas de Língua Portuguesa pela FFLCH-USP. Atualmente, cursa doutorado no mesmo Programa de Pós-graduação. Professora da rede pública municipal, agitadora cultural e mediadora de leitura, coordena projetos de literatura no Jardim São Savério, na periferia da Zona Sul de São Paulo. Em 2008, publicou De passagem, mas não a passeio (Global Editora), livro do qual foi extraído este poema. 
E era pra saber tudo

Sem livro, sem sol, sem estradas.

Mas eu vi pele de homem

Abrindo-se em mais palavras.

E era pra estar suspensa

(A lógica é um poço profundo)

Mas eu vi pele de homem

Querendo voltar ao útero.

\section{RAPente registado no Jd. Jaqueline}

Allan da Rosa ${ }^{4}$

A necessária gambiarra, o truque no precário

Com uma mão de farinha um bolo de aniversário

Barão, quem tá + vazio? Teu coração ou meu armário?

Os ponteiros tic tac enquadrando no horário

Do vaqueiro no sertão até a extra do operário

Dia a dia de jiló nessa merreca de salário

E a ganância da mansão faz o seu itinerário

A mesma que anuncia e manda no noticiário

Como é fácil pros herdeiros ser universitário

E meu sangue Kaigang, índio incendiário

Angoleiro de quilombo, de mocambo libertário

Na terra a criação, na Bovespa o adversário

Das contas no chão um caxixi ou um chocalho

Um samba na Barra Funda, um répi no Educandário.

4. Allan Santos da Rosa nasceu no municípío de Taboão da Serra, na Grande São Paulo, em 1976. É mestre em Educação pela FE-USP e graduado em História pela FFLCH-USP. Já atuou em diversos projetos de educação não formal. Poeta ativista, frequenta diversos saraus, como Cooperifa, Binho, Poesia na Brasa e Elo da Corrente. Criou a Edições Toró em 2005, selo pelo qual publicou três livros: Vão (do qual foi extraído este poema), em 2005; Da Cabula, em 2006; A Calimba e a Flauta, em parceria com Priscilla Preta, em 2012. Em 2007, publicou Zagaia (Editora DCL). 


\section{Campo Limpo Taboão}

Binho $^{5}$

Quando nasci tinha seis anos.

No lugar em que nasci,

Sonhava que era tudo nosso.

Tinha os campinhos e os terrenos baldios.

Era meu território.

Já foi interior,

Hoje periferia com as casas cruas.

As vacas com tetas gruas

Não existem mais.

A cerca virou muro. Óbvio.

A cidade cresce.

O muro cresce.

Vieram os prédios, as delegacias, os puteiros

$\mathrm{E}$ as Casas Bahia.

Também cresci,

Fiquei grande.

Já não caibo dentro de mim

E de tão solitário

Sou meu próprio vizinho.

E de tão solitário

Sou meu próprio vizinho.

5 Robson Padial, o Binho, nasceu em São Paulo em 1964. Há mais de vinte anos é ativista cultural na região do Campo Limpo, na periferia da Zona Sul de São Paulo. Em 2004, criou o Sarau do Binho que, até 2012, acontecia em um bar de sua propriedade. Obrigado a fechar as portas do boteco devido a perseguições do poder público, hoje realiza o sarau no Espaço Clariô, em Taboão da Serra. Publicou em 2007, em parceria com Serginho Poeta, Donde Miras - Dois poetas e um caminho (Edições Toró), livro do qual foi extraído este poema. 


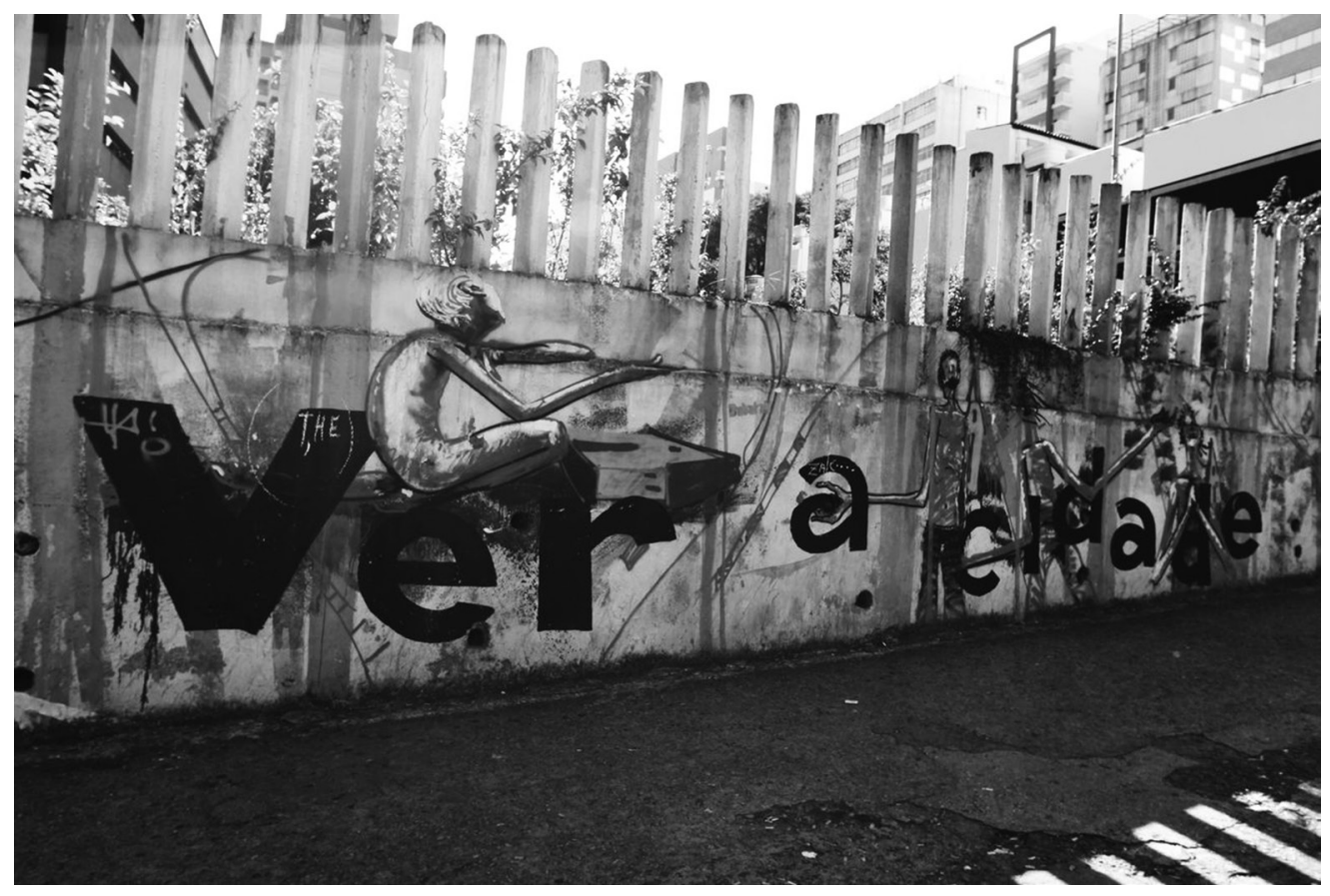

Imagem. Sérgio Nem. Fotografia: Guma 